\title{
Three-dimensional Accounting Control Model under ERP Condition
}

\author{
Liu Songyue, He Shangyang \\ Wuhan University of Technology, Wuhan Hubei, China, 430200
}

Keywords: ERP condition; three dimensional; accounting control model

\begin{abstract}
With the rapid development of market economy, enterprises are facing increasingly fierce market competition environment, in order to enhance their comprehensive competitiveness, enterprises must constantly improve the internal management model, improve management efficiency. On the basis of the three-dimensional process model of ERP, facing the great changes of accounting control conditions in enterprises after the implementation of ERP system, in order to ensure the effective conduct of economic activities and ensure the authenticity and integrity of accounting information, the author deeply ponders on the reconstruction of the internal accounting control system structure and designs a three-dimensional accounting control system model to improve the internal accounting control under ERP conditions, and provide a reference for enterprises implementing ERP system.
\end{abstract}

\section{Introductions}

As an important part of the new control conditions, ERP system has gradually affected the internal control elements such as the accounting system control procedures after running on-line in various enterprises. In view of the new changes of the internal accounting control environment under ERP, this paper designs a three-dimensional dynamic internal accounting control system model for enterprises implementing ERP system, and analyzes the control mechanism of the model from three dimensions.

\section{The ERP system challenges the traditional accounting control of enterprises.}

ERP system is built on the basis of information technology, using the advanced management ideas of modern enterprises, integrated all the information resources of enterprises, and provided a comprehensive, integrated and dynamic management platform for decision-making, planning, control and business performance evaluation. Its essence is highly integrated management based on the process, which not only breaks the process division of the original functional departments of the enterprise, but also realizes the unified management and sharing of enterprise resources. The application of ERP system challenges the traditional internal control of enterprises. Firstly, the internal risk environment of enterprises has changed. The control risk based on manual approval in the past has become more complex with the introduction of ERP system. Two, we need to optimize 
and restructure business processes and organizational structure. Before the implementation of ERP system, many enterprise business systems were designed around a business function rather than based on cross-departmental processes. The bottleneck of each business process seriously affected the optimal allocation of enterprise resources. After the implementation of ERP, the integrated process processing of business of each functional department can be realized. Through integration, ERP systems can optimize processes, thereby reducing or merging repetitive, non-value-added processes. Because the duplicate links which are beneficial to control in the original manual business process disappear, many supervisory clues of internal control also disappear, so the changes of internal control system will inevitably impact on the effectiveness of the original accounting control system.

\section{The design of the traditional accounting control system model under the condition of ERP}

In the traditional accounting control model (generally two-dimensional control model), the first dimension is a kind of regulation control based on system, which regulates the static control of accounting quality according to the three links of accounting information input, processing and output. The second dimension is the reflection control of accounting on production and operation process. Under the ERP system, the environment of accounting control has changed greatly. It is a new control environment which combines the specific organizational structure, management ideas, management mode with the network system and database structure. In ERP environment, the processing and output of business and accounting data are highly integrated in the system, and are automatically managed and controlled by the system. Input of business raw data naturally becomes the focus of accounting quality control. Therefore, in order to ensure the realization of the goal of internal accounting control, we must reconstruct the model of enterprise accounting control system from the new characteristics of the control environment.

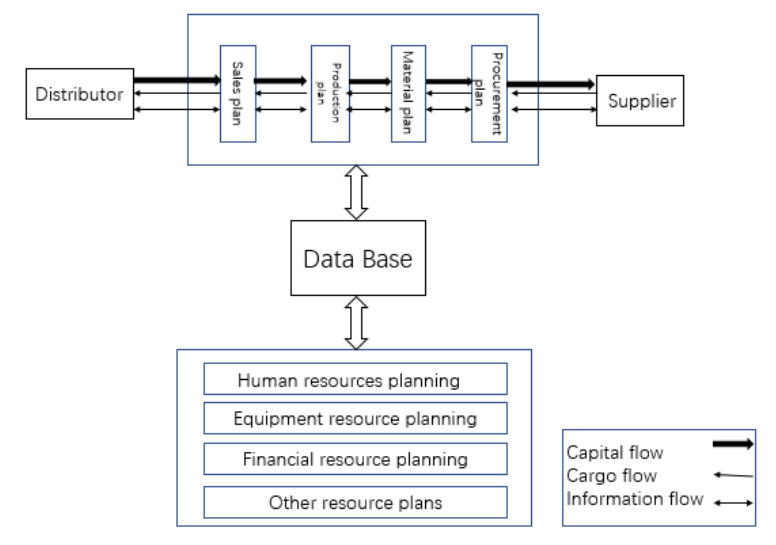

Figure 1 Three dimensional model of ERP

The accounting control model under ERP condition is a real-time dynamic control model based on the business environment, management concept, management mode and business process requirements. To reconstruct the accounting control model, we need to fully mine the real-time dynamic control requirements and control rules for each business process, and determine the real-time dynamic control links, control elements, control methods and control processes for each business process. According to the characteristics of ERP system, such as high integration, real-time dynamic and logistics, capital flow, information flow "three-in-one" and its requirements for accounting control, internal accounting control should be divided into three dynamic dimensions: enterprise human universal control, information system universal control and business and accounting universal control. The three-dimensional process model of the ERP system established 
from these three dimensions is shown in Figure 1.

\section{The structure analysis of three dimensional structure accounting control model}

The first dimension: the universal control dimension of corporate culture. Although ERP system has powerful management and control functions, it is only a management tool for managers after all, but also requires high-quality staff to actively cooperate in order to play a role. Excellent and advanced enterprise culture, honest and trustworthy moral conduct, perfect and effective personnel policy are the foundation of internal control model reorganization under ERP environment. The control object of this dimension is mainly the employees of the enterprise; the control goal is to effectively make the overall goal of the enterprise become the concrete goal of the employees; the control measures are mainly to control the behavior of the employees through effective systems, strengthen the employees' recognition of the enterprise through the enterprise beliefs and values, and enhance the cohesion of the enterprise. Improve the consistency of the overall objectives of the enterprise and the specific objectives of employees; through effective personnel incentive policies to make the overall objectives of the enterprise become the standard of self-requirements of managers. The author believes that enterprise universal control must be based on enterprise system control. If there is no powerful advanced system to regulate enterprises and employees, the management of enterprises will be chaotic and disorderly, and the universal control of enterprise humanities will be impossible to talk about.

The second dimension: the universal control dimension of information system. Different from the traditional accounting information system structure, ERP system structure has the characteristics of highly integrated business, real-time data processing and highly shared information, which makes the scope of accounting information system control expanded, and the complexity and difficulty of control increased. In order to ensure the correctness, consistency, integrity and security of enterprise business and accounting information under ERP environment, a complete set of universal control dimensions of information system must be added in the reconstruction of enterprise internal accounting control architecture. The object of its control covers the entire ERP information system (system network, system hardware equipment, software system, database, computer room and departments and personnel who use and maintain the system). The main control objectives are: to ensure that the system is safe, reliable and effective; to ensure that business and accounting processing is correct, complete and consistent; to ensure that business and accounting information output is correct and safe; \$to ensure the safety and integrity of the ERP database; to ensure that the ERP system has a certain ability of disaster prevention, relief and recovery; The unauthorized person can not operate to maintain the normal operation of the system, and ensure the safety of the network and e-commerce.

Third dimensions: the general control dimension of business and accounting. The dimension of universal control of business and accounting has intersections with that of traditional internal accounting control system. In ERP environment, business and accounting control activities and corresponding control methods, measures and procedures depend on the reorganization of business processes in the process of ERP implementation. If business and accounting universal control dimensions are constructed, it is necessary to take advantage of the unique embedded control mechanism advantages of ERP system to better support business and accounting control activities.

\section{Innovation of financial management function based on erp}

\subsection{Data acquisition function innovation}

Because of the poor integration of data information in traditional financial management system, 
the same information may be entered in several subsystems at the same time, which is easy to cause confusion of information, resulting in the decentralization and isolation of information, and unable to form systematic financial information data. The financial management system based on ERP can realize the integrated processing of financial information, standardize the processing of financial management information, strictly standardize the input of original data and analysis results, ensure that each data has a unique input channel, information will not be repeated and will not be missed, and ensure that the data can be guaranteed. Accuracy. The innovation of information integration function of ERP system is mainly embodied in its information processing and refinement. Only in this way can we meet the needs of different information users and ensure the accuracy and integrity of information to the greatest extent.

\subsection{Financial budget function innovation}

Affected by the planned economy system, many enterprises do not have enough cognition and attention to the financial budget management. Some enterprises carry out the financial budget, only take the past sales data as the basis of the budget, take the sales forecast as the starting point for the financial budget preparation, but this kind of preparation results often have. Great flexibility, and the accuracy is not high, but also easy to lead to financial management information between enterprises can not be effectively transmitted. The financial budget under ERP environment is driven by the market and based on the production plan of the enterprise, the budget function is analyzed in detail from the financial point of view, and the corresponding budget management system is formulated to ensure that the budget of the enterprise is effectively implemented and strictly controlled, so as to achieve the goal of enhancing the comprehensive competitiveness of the enterprise. Therefore, the financial budget innovation based on ERP is mainly reflected in the importance of ERP to the enterprise financial budget and the source of budgeting data. Persisting in market-oriented budgeting can provide more reliable information for enterprise investors and financing plans.

\subsection{Internal control function innovation}

Internal control is the whole process of control measures within the enterprise, the main purpose is to ensure the integrity and security of management data. In the traditional financial management environment, the internal control of enterprises is mostly through personnel authorization, approval and other links to carry out internal control means, which requires more time and effort. The innovation of internal control function of enterprise financial management based on ERP has broadened the scope of internal control and enriched the means of internal control. By means of control measures such as password authorization, the influence of production and operation activities of enterprises under internal control has been reduced, the efficiency of internal control has been improved, and the integrity and authenticity of financial information has also been enhanced.

\section{Conclusion}

To sum up, the enterprise financial management based on ERP is an advanced management which conforms to the law of the development of modern market economy, and is also an inevitable choice for our enterprises to implement financial management activities. Enterprise management activities carried out under the ERP environment have realized effective innovation in data collection, financial budget and internal control, greatly improving the efficiency of enterprise financial management, enhancing the comprehensive competitiveness of enterprises to participate in 
market competition, and promoting the sustainable and stable development of enterprises

\section{Acknowledgment}

National College Students' innovation and entrepreneurship training program (20181049711004)

\section{References}

[1] Robert W. Scapens, Mostafa Jazayeri. ERP systems and management accounting change: opportunities or impacts? A research note [J]. European Accounting Review, 2003, 12(1):201-233.

[2] Grabski S V, Leech S A, Schmidt P J. A Review of ERP Research: A Future Agenda for Accounting Information Systems [J]. Journal of Information Systems, 2011, 25(1):págs. 37-78.

[3] Lea B. Management accounting in ERP integrated MRP and TOC environments [J]. Industrial Management \& Data Systems, 2007, 107(8):1188-1211.

[4] Kanellou A, Spathis C. Accounting benefits and satisfaction in an ERP environment [J]. International Journal of Accounting Information Systems, 2013, 14(3):209-234.

[5] Kholeif A O R, Abdel-Kader M, Sherer M. ERP Customization Failure: Institutionalized Accounting Practices, Power Relations and Market Forces [J]. Social Science Electronic Publishing, 2014, 3(3):250-269(20).

[6] Sánchez-Rodríguez C, Spraakman G. ERP systems and management accounting: a multiple case study [J]. Qualitative Research in Accounting \& Management, 2012, 9(4).

[7] Akroyd C, Askarany D, Spraakman G. ERP Systems and Management Accounting: A Methodological Note from a Multiple Case Study [J]. Social Science Electronic Publishing, 2014.

[8] Liu G Y. Accounting Experimental Teaching System Reconstruction Based on ERP [J]. Research \& Exploration in Laboratory, 2009.

[9] Morris J J. Measuring the impact of Enterprise Resource Planning (ERP) systems through the prism of accounting theory [J]. Dissertations \& Theses - Gradworks, 2009.

[10] O'Leary D E. Enterprise Resource Planning (ERP) Systems: An Empirical Analysis of Benefits [J]. Accounting Horizons, 2011, 1(1). 